\title{
RIDE-THROUGH-FAULT CAPABILITIES OF DFIG WIND FARM CONNECTED TO A VSC STATION DURING A DC FAULT.
}

\author{
D. Campos-Gaona ${ }^{* \Delta}$, E.L. Moreno-Goytia ${ }^{*}$, O. Anaya-Lara ${ }^{\dagger \oplus}$, G. Burt ${ }^{\dagger \oplus}$ \\ *Instituto Tecnológico de Morelia,Mexico ${ }^{\triangle}$ davidcg@ieee.org, ${ }^{\ddagger}$ elmg@ieee.org \\ ${ }^{\dagger}$ Strathclyde University, Scotland ${ }^{\oplus}$ olimpo.anaya-lara@eee.strath.ac.uk, ${ }^{\Phi}$ gburt@eee.strath.ac.uk
}

Keywords: DFIG, OFFSHORE, VSC, DC-FAULT.

\begin{abstract}
.
This work analyzes the capabilities of ride-through-fault (RTF) of a double-fed induction machine (DFIG), -based wind farm connected to a VSC-, in case of a fault in the DC side of the VSC. The modelling of the DFIG wind turbine takes into account key aspects that intervene in succeeding the fault ride-through such as the power capacity of its electronic converter and its control scheme. As result a better understanding of the behaviour and capabilities of such system to perform a successful RTF is achieved. This work also analyzes the behaviour of the momentary islanding of the system composed by the wind farm and the ac filters of the VSC station. Using that information, a novel control scheme for the offshore VSC station is proposed in order to enhance RTF capabilities of the wind farm in case of such DC faults.
\end{abstract}

\section{Introduction.}

With the increasing penetration of wind power into electrical grids, DFIG wind turbines have become the leading technology in market because of their variable speed feature, which compared to fixed-speed generators, offer benefits such as reduction of mechanical stress, improved power quality, improved system efficiency, reduction of acoustic noise and cost effectiveness. The principle of the DFIG wind turbine is that rotor windings are connected to the grid via slip rings and a back-to-back voltage source converter that controls both, the rotor and the grid currents. By controlling the rotor currents of the converter, it is possible to adjust the active and reactive power fed to the grid from the stator, independently of the generator's turning speed. As a result, the machine can operate in a range of speeds around 35\% above and below of the synchronous speed, with the advantage of using a power electronic converter of around $30 \%$ the power rating of the turbine, meaning a decrease in the cost and size of the whole system. The coming installation of wind farms mostly includes offshore turbines, where winds can be faster, more constant, and less turbulent. Furthermore, larger wind turbines can be used without impediments that affect the onshore wind farms such as space, acoustic noise and visual pollution. The largest power turbines designed for offshore wind farms on date are based in DFIG technology, such as the RePower Systems 6M of 6Mwatts[1].

\section{The use of DC in offshore wind farms power transmission and its grid code compliance.}

Some of the next-to-come offshore wind farms will be located more than $100 \mathrm{~km}$ away from shore and are planned to deliver up to $1 \mathrm{GW}$ [2]. Connecting them to the inland $\mathrm{AC}$ electrical network via underwater cables presents at least 3 weak points:

1. The need of large amount of capacitive reactive power. The capacitive charging current is proportional to the length and the voltage of the $\mathrm{AC}$ cable and beyond a certain distance there is no capacity left for the active power transmission.

2. Synchronous operation of wind farms and the AC grid.

3. Propagation of voltage and frequency fluctuations to the $\mathrm{AC}$ network due to the variation of the wind.

Several studies have identified the advantages of using DC for offshore power transmission, such as full power flow control, fewer cables, lower power losses and, more importantly, no limitation in transmission distance by cable charging currents. The transmission can be either using conventional High Voltage Direct Current (HVDC) which is based in line commutated converters or in VSC. Several advantages of the VSC systems over the conventional HVDC systems have been found to be better suited for offshore wind farms such as fast and independent active and reactive power control, the capacity of variable frequency operation, black start capabilities, allowance of multi-terminal network structures and the capacity of fast mitigation of power quality disturbances[3]. A simplified line diagram of a VSC link is shown in Figure 1.

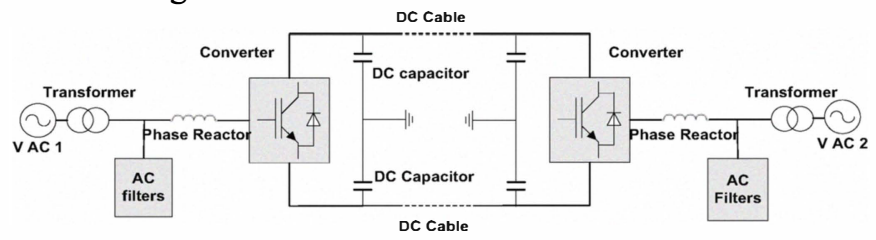

Figure 1: Line diagram of a HVDC-VSC link.

2.1 Grid compliance of the VSC-based power transmission of DFIG wind farms.

Given the power rating of the offshore wind farms to be installed, some countries have issued dedicated grid codes for connecting the wind turbines/farms to the electrical network 
addressed to transmission and/or distribution systems. In most of the cases, e.g. Denmark, Germany, and Ireland, these requirements have focused on power controllability, power quality, and RTF capability [4]. Several studies have used the fast control action of the VSC converter to give support to the grid in case of a fault on the AC network, while carrying out a successful RTF of the DFIG wind farm, thus proving the efficiency of the VSC based power transmission for grid-code compliance [3]. In the other hand, the design of the DFIG wind turbine also includes RTF capabilities that allow the wind turbine to remain connected during grid faults inside the wind farm network. A widely used method is the crowbar (CB) protection, which allows the disconnection of its turbine-associated power electronic converter, which helps to protect converter from the rotor induced transient currents, while adding external impedance to the rotor windings. Several investigations have shown the effectiveness of the electronic converter control of the DFIG and the CB protection to perform a successful RTF [5]. However an aspect that has been constantly overlooked in studies is the RTF capability of the VSC-connected DFIG wind farm in case of a DC fault. The implication of a DC fault in a VSCconnected DFIG wind farm is reviewed next.

\section{The DC fault in a VSC station.}

For proper operation each solid-state switch of the power electronics structure of a VSC includes an anti-parallel diode. When a fault conditions occurs on the DC line, the DC capacitors of the VSC quickly discharged to ground voltage failing to back bias the anti-parallel diodes, which in consequence start to drive the fault current towards the fault incidence point, as seen in Figure 2. Under this situation, the VSC by its own is not capable of interrupting the AC power from feeding the fault current through the diode rectifier bridge made by the anti-parallel diodes. In such circumstances the interruption of the fault current should be carried on by an external circuit breaker installed at the AC sides of both VSC terminals, including that connected to the wind farm, leaving it disconnected without a voltage reference from the VSC station for a period of time.

A fault in an underwater DC cable hardly can be transient; instead the chances are it is a permanent fault due cable damage, meaning a permanent disconnection of the wind farm. Nevertheless the faults in the DC side of the circuit can happen inside the VSC station facilities such as short circuits in the DC capacitor terminals, the power converter semiconductor terminals or in the poles of the VSC stations. In such case, the AC circuit breakers can open to try to deionize the electric arc and free the fault.

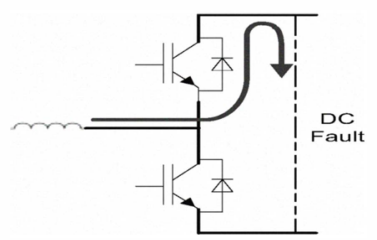

Figure 2: Path of the fault current in a DC side fault.
In the other hand, future plans for offshore wind farms consider the option of creating multi-terminal DC networks[6], where, in case a permanent fault of one of the cables forming the network occurs, it will be required to stop the power flow to the faulted point by disconnecting such section from the rest of the network. The use of DC circuit breakers for interrupting the current flow to the faulted cable is not yet feasible because DC circuit breakers capable of interrupting such high currents still don't exist, and are not going to be an attractive option economically speaking in the medium term[7]. Instead, some proposals address the problem using the AC circuit breakers of the VSC stations to interrupt the power flow to the fault point and then use fast DC switches to disconnect the faulted cable[7]. In such cases the wind farms of the multi-terminal network will be subjected to a momentary disconnection from the VSC stations.

Finally, in case the wind farm is located inland connected via overhead DC lines to the grid, then the chance of a fault in the DC lines increase. In such cases studies have proven that most of these faults are transient in nature and can be cleared by a short interruption of the power flow to the fault point [8], implying again a momentary disconnection of the wind farm from the VSC station.

\section{Analysis of the behaviour of a DFIG wind farm subjected to a momentary disconnection form the VSC station.}

When the VSC suffers a DC fault, the voltage in the DC link quickly decreases, accordingly to the type of fault; in any case large currents will circulate through the anti-parallel diodes of each IGBT valve. When this over currents are detected, a fast over current protection is used to immediately block the IGBT valves (this protection is much faster than the AC circuit breakers). The blocking of the IGBTs has as consequence a total loss of the voltage reference of the wind farm. A sudden loss of the voltage reference, just as in the occurrence of three phase fault, causes large transient currents in the stator windings of each DFIG. This transient currents will induce large transient currents to the rotor windings as well, by the law of conservation of flux, which are large enough to trigger the crowbar protection. This implies leaving uncontrolled the speed and the reactive power consumption of the wind turbine for a period of time.

The relationship between voltage and torque can be found from the electromagnetic torque equation of an induction machine, which in steady state is defined as:

$$
T_{e m}=\frac{3}{\omega_{s}} \frac{R_{r}^{\prime}}{s}\left[\frac{\left|V_{s}\right|^{2}}{\left(R_{s}+\frac{R_{r}^{\prime}}{s}\right)^{2}+\left(X_{s}+X_{r}^{\prime}\right)^{2}}\right]
$$

Where $T_{e m}$ is the electromagnetic torque, $\omega_{s}$ is the synchronous speed, $I_{s}$ is the stator current $R_{r}^{\prime}$ is the equivalent rotor resistance seen from the stator circuit, $S$ is the slip speed, $V_{s}, R_{s}, X_{s}$ are stator's voltage, resistance and 
reactance respectively and $X_{r}^{\prime}$ is the equivalent rotor's reactance seen from the stator circuit.

Equation (1) shows that the electromagnetic torque developed inside an induction generator, at any given speed, is proportional to the square of the terminal voltage. This means that a reduction in the terminal voltage conveys a further reduction of electric torque.

The mechanical torque produced by the wind can be considered constant during the fault period (the time constant of the pitch control are much larger that the electrical torque), thus the dynamic behaviour of the rotor speed can be described by the movement equation of the induction machine, which, in the case of a single mass system, is defined as:

$$
\omega_{r}=\frac{1}{2 H} \int\left(T_{M}-T_{E}\right) d t+\omega_{r 0}
$$

Where $H$ is the constant of inertia of the rotor mass in seconds, $\omega_{r}$ is the rotor angular speed in P.U., $T_{M}$ is the mechanical toque in P.U. applied to the rotor and $T_{E}$ is the electrical torque of the machine in P.U. and $\omega_{r 0}$ is the initial value of the rotor angular speed.

Equation (2) shows that, if it is the case the electrical torque is less than the mechanical torque, the angular speed increments accordingly to a slope proportional to the difference between mechanical and electrical torque. In the case of a DC fault, the voltage collapse to 0 , meaning the highest rate of change of the speed. If the slip speed increments beyond a critical stability point, the machine looses synchronisms, and the electrical toque collapses permanently. In order to avoid reaching the critical stable point, the crowbar protection connects added impedance to the rotor windings $\left(R_{c b}\right)$ which modifies the speed-torque characteristic curve of the induction machine accordingly to Equation 3.

$$
\pm S_{\text {max }}=\frac{ \pm\left(R_{r}^{\prime}+R_{c b}\right)}{\left(R_{r}^{\prime}+R_{c b}\right)^{2}+\left(X_{s}+X_{r}^{\prime}\right)^{2}}
$$

Where the maximum slip speed $S_{\text {max }}$ is directly proportional to the magnitude of $R_{c b}$. Therefore, the machine can over speed beyond its nominal critical stability point without losing synchronism. The normal practice is to use crowbar impedances of the range between 0.5 P.U. to 1 P.U. allowing an over speed up to ranges between 2.5P.U. to 4.5 PU.

At higher speeds larger currents are induced in the rotor windings and thus larger voltages are needed to control them. When the rotor speed is above the synchronous speed, active power is generated in the rotor windings which is absorbed by the rotor side converter (RSC) and delivered to the grid by the grid side converter. The fundamental aspect for archiving a successful RTF is the capability of the RSC of the DFIG to control the rotor speed after the crowbar protection is deactivated. This capacity is, however, limited by the power rating of the converter which allows a much smaller over speeding than the crowbar protection. The factors that affect the rotor speed after the fault are:

1) The time duration of the fault. The longer the voltage reference is 0 , the more the rotor over-speeds.

2) The wind speed before the fault. The rotor speed is set by the power electronic converter accordingly to the present wind speed in order to archive a maximum power tracking.

3) The transient currents induced in the stator windings after the fault is cleared. When the voltage reference is restored, again high transient currents are induced by the sudden change of voltage level and the huge reactive power consumption of the IMs to re-magnetize their air gaps, triggering again the crowbar protection and leaving the machine uncontrolled for a further period of time. These transient currents may be even higher than those generated at the beginning of the DC fault.

For this investigation a Simulink-based tailor-made model of an aggregated DFIG wind farm that takes into account the electronic converter power rating precisely, is used. The model uses the "two degree of freedom internal model control (IMC)" control technique for the DC voltage controller of the grid side converter in order to maintain the DC voltage level almost without variations even in the worst case faults. Thanks to this, a limit for the DC current that the grid side converter can convert and deliver to the grid can be set. This current, multiplied by the constant DC voltage is $30 \%$ of the rated power of the wind turbine. A block diagram of the controlled is shown in Figure 3, where $F(s)$ is the IMC controller, $G_{a}$ is the active conductance for load disturbance rejection, $C$ is the capacitance, $s$ is the laplace operator $W$ is the energy of the capacitor, $v_{d c}$ is the DC voltage $V_{d_{-} g s c}$ is the $\mathrm{d}$ component of the voltage generated by the grid side converter, and $\mathrm{Pr}$ is the power coming from the rotor.

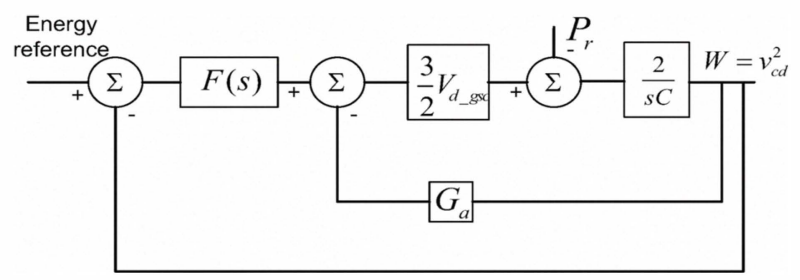

Figure 3: Two degrees of freedom IMC for the DC voltage.

The values of $F(s)$ and $G_{a}$ are as follow:

$$
\begin{gathered}
F(s)=-\frac{\alpha C}{3 V_{d_{-} g s c}}-\frac{\alpha G_{a}}{s} \\
G_{a}=\frac{\alpha C}{3 V_{d_{\_} g s c}}
\end{gathered}
$$

Where $\alpha$ is the closed loop bandwidth of the controller, which can be calculated to set the minimum allowed error signal diversion, in this case the minimum voltage is stated to be 0.9 of the reference voltage $\left(v_{d c}^{r e f}\right)$, giving as a result a $\alpha$ of: 


$$
\alpha>\frac{2 P_{r_{-} \max } e^{-1}}{0.19\left(v_{d c}^{r e f}\right)^{2} C} \approx \frac{3.87 P_{r_{-} \max }}{\left(v_{d c}^{r e f}\right)^{2} C}
$$

\section{Study cases.}

A network with a 200MW VSC station connected to a $200 \mathrm{KV}$ DC link has been implemented in Simulink. The line diagram of the simulated network is presented in Figure 4. The control dynamics of the onshore VSC station are not considered in this investigation and are assumed to restore the DC voltage after the DC fault has cleared. The voltages in the simulation are represented as $d$ and q vectors with the $d$ vector aligned to the AC voltage. The data for the aggregated wind farm model is one of a 1.5 Mwatt DFIG.

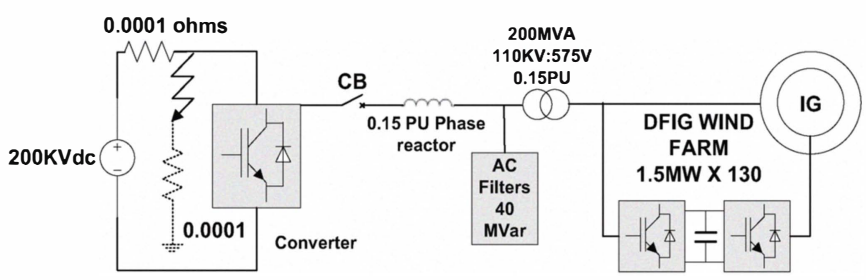

Figure 4: Simulated network.

Case of study 1: A successful RTF. Figure 5 shows the simulation of a DFIG wind farm in case of a DC fault in the second 3 lasting for $120 \mathrm{~ms}$. The wind farm has an incoming wind speed of $10 \mathrm{~m} / \mathrm{s}$ meaning a maximum mechanical torque of 0.548 P.U. for a $1.5 \mathrm{MW}$ wind turbine when the rotor speed is at 1.091P.U.

At the moment of the fault, the AC voltage drops to a very low value because of the sudden drop of the DC voltage. Just a few milliseconds after the fault, the IGBT valves block and the circuit breaker opens, causing the voltage reference to be lost completely in the wind farm network. The induced stator currents trigger the $\mathrm{CB}$ protection and the rotor voltage drops to 0 , meanwhile the machine begins accelerating.

When the CB protection is activated the grid side converter power drops to 0 , because there is no currently energy being transfer to/from the RSC. The crowbar protection deactivates after $50 \mathrm{~ms}$ allowing the RSC to try to control the rotor speed, however it is unsuccessful because there is still no electric torque produced, and meanwhile the magnitude of the voltages injected by the RSC keep increasing, trying to artificially create the stator flux that performs the control action. $70 \mathrm{~ms}$ after, the fault disappears and the VSC station is connected again to the DFIG wind farm. The transient currents induced in the stator windings of the machines are of larger magnitude, causing again the activation of the $\mathrm{CB}$ protection and creating large oscillations in the rotor speed. The duration of the transient currents is large enough to keep triggering the $\mathrm{CB}$ protection for an extended period of time, however, the rotor speed doesn't reach a speed unable to control, and after the transient currents have decreased, (after $570 \mathrm{~ms}$ ) the RSC can take control of the currents without reaching is power rating limit.

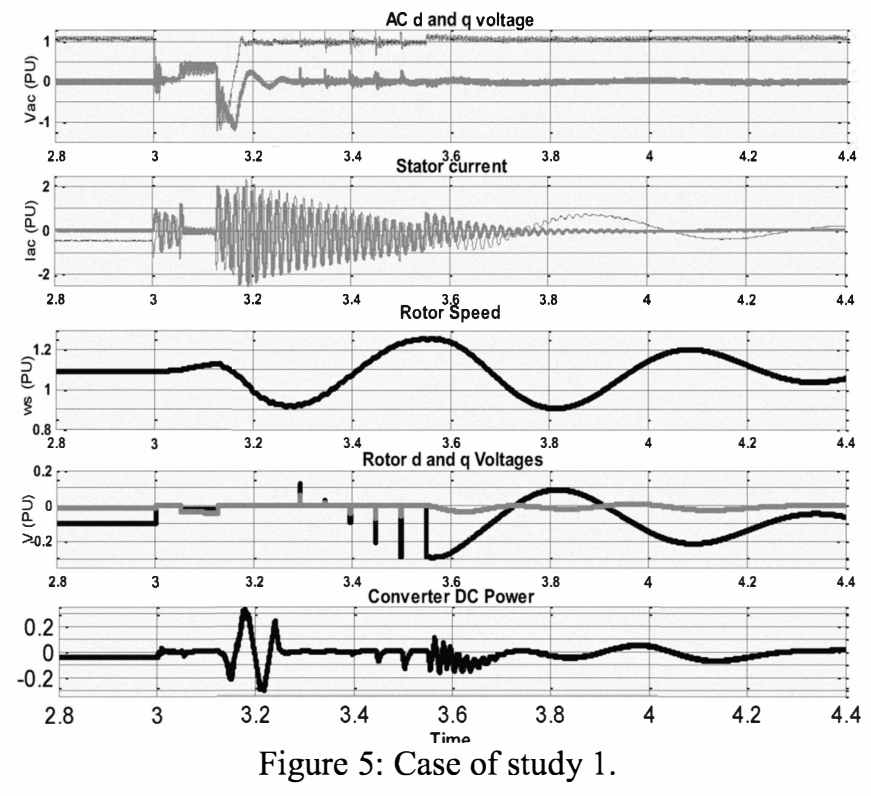

Case of study 2: An unsuccessful RTF. In Figure 6 a second case of study is presented. Here the time duration of the DC fault is set to $200 \mathrm{~ms}$ and the wind farm has an incoming wind speed of $12 \mathrm{~m} / \mathrm{s}$, meaning a maximum input mechanical torque of 0.948 P.U. when the rotor speed is at 1.31 P.U. The grid side converter is using all its power to deliver the energy from the rotor windings. At the moment of the fault the speed was set to a higher than in the case of study 1 , and the rate of change of the speed is higher because the mechanical torque is bigger that the first case. When the grid side converter tries to regain control of the speed at $4.2 \mathrm{~s}$ the rotor speed is already too high and the $\mathrm{CB}$ protection activates leading a further over speed or the rotor.

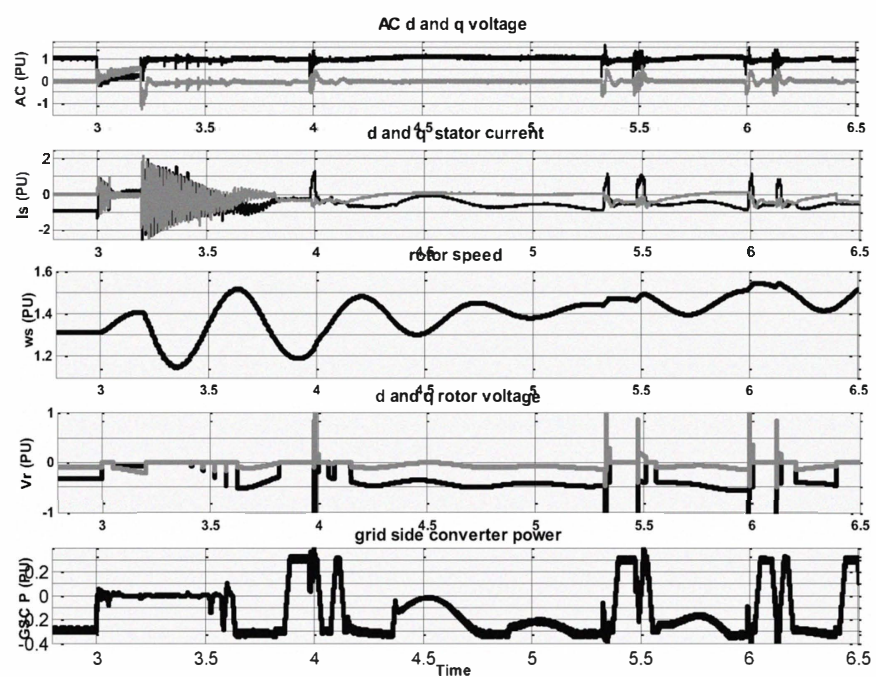

Figure 6: Case of study 2.

\section{A new VSC control technique to enhance the RTF of the DFIG wind farm.}

During a DC fault, the crowbar protection deactivate faster than the usual time a DC fault disappears, and, as explained 
before, the RSC then tries to artificially create a stator flux to perform the desired control actions. The action of the RSC is reflected as a small voltage appearing in the stator windings.

The magnitude and the frequency of this voltage are dictated by the voltage equation of the IM and the complex process of interaction between the DFIG and the left passive elements of the network (trying to attain a self exited system). The voltage of the induction machine in the islanded system, ignoring the stator resistive drop, is reduced to:

$$
U_{s}=\sqrt{3} \varphi_{s} \omega_{s}
$$

Where $U_{s}$ represents the rms value of the line-to-lne voltage and $\varphi_{s}$ is the rms flux linkage per stator phase and $\omega_{s}$ is the angular frequency.

Trying to calculate the newly created voltage magnitude and frequency is a complex task; however simulations show that it has a frequency close to the nominal value. Following the frequency of this newly developed voltage using the already tuned phase lock loop of the control systems of the DFIG is attainable. If the frequency of this voltage is used by the VSC to create the post fault voltage reference, the outcome is a transient current of lesser magnitude; this is because the change of the voltage reference at the stator windings is less abrupt. The result of using this technique, named here as "Frequency Matching", is shown in Figure 7, where the same settings of the case of study 1 are used.

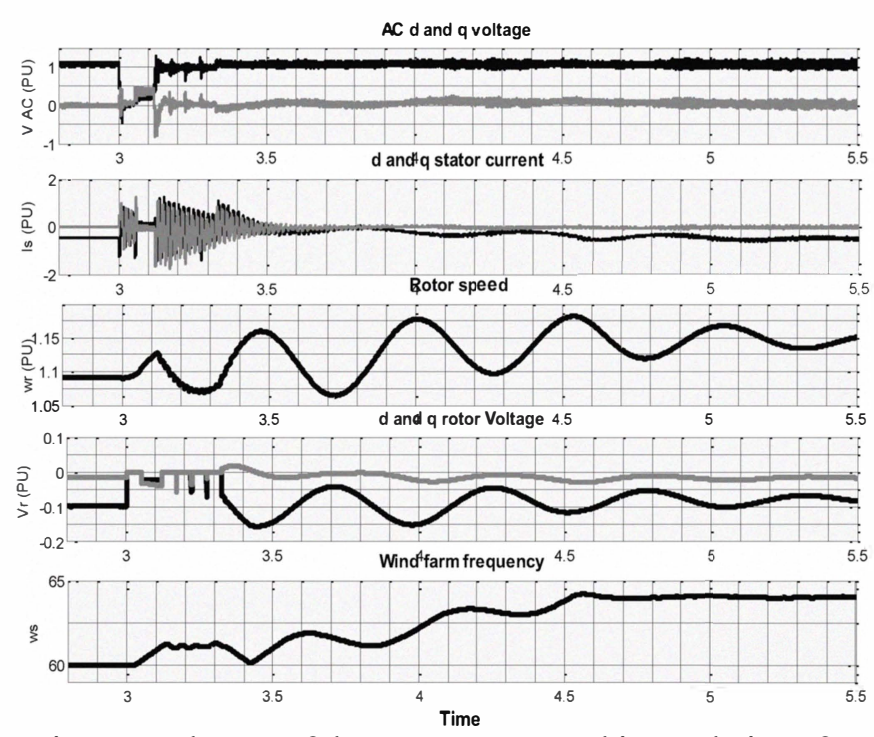

Figure 7: The use of the Frequency Matching technique for the case of study 1 .

The result is the magnitude of the transient currents decrease from 2.55 P.U. at its peak, seen in the case of study 1 , to 1.28P.U. Also the rotor speed decreased from the peak of 1.26 to a peak of 1.18 because the transient in the electric toque is not as large as in the first case. Finally the time the crowbar protection is active after the fault disappears also decreases because the transient currents are smaller in time and magnitude. In this case, the RSC regained full control at 3.32s. In the first case of study, full control was regained not until 3.54s. The frequency of the wind farm begins increasing and is later established by the "Frequency Matching" controller to work at $64 \mathrm{~Hz}$.

\section{Conclusions.}

The capability of an offshore DFIG wind farm to RTF successfully depends primarily of the power capacity of the electronic converter of the turbine, the pre-fault wind conditions, and the control technique of the VSC station after the wind farm is re-connected to its terminals. Using the control technique described in this paper enhances the capabilities of the wind farm to accomplish a successful RTF using the frequency control of the VSC station.

\section{References.}

[1] REpower_Systems_AG. (2010, 6M the futher development of the succeessful offshore turbine REpower $5 M$ [Brochure]. Available: http://www.repower.de/fileadmin/download/produkte/R E 6M.pdf

[2] X. Dawei, et al., "Coordinated control of an HVDC link and doubly fed induction generators in a large offshore wind farm," Power Delivery, IEEE Transactions on, vol. 21, pp. 463-471, 2006.

[3] X. Lie, et al., "Grid Integration of Large DFIG-Based Wind Farms Using VSC Transmission," Power Systems, IEEE Transactions on, vol. 22, pp. 976-984, 2007.

[4] F. Iov, et al., "Mapping of grid faults and grid codes," Risø National Laboratory, Roskilde, Denmark 2007.

[5] X. Bing, et al., "Study of fault ride-through for DFIG based wind turbines," in Electric Utility Deregulation, Restructuring and Power Technologies. IEEE International Conference on, 2004, pp. 411-416

[6] Airtricity. (2005, European Offshore Supergrid Proposal [Report]. Available: http://www.trecuk.org.uk/resources/airtricity supergrid V1.4.pdf

[7] T. Lianxiang and O. Boon-Teck, "Locating and Isolating DC Faults in Multi-Terminal DC Systems," Power Delivery, IEEE Transactions on, vol. 22, pp. 1877-1884, 2007.

[8] D. Naidoo and N. M. Ijumba, "HVDC line protection for the proposed future HVDC systems," in Power System Technology, 2004. PowerCon 2004. 2004 International Conference on, 2004, pp. 1327-1332 Vol.2.

\section{Authors.}

David Campos-Gaona. He received the B.E. and M.Sc. degrees from Morelia Technological Institute, Mexico in 2004 and 2007 respectively. He is currently pursuing a Ph.D. in the same institution. His areas of research are wind farms, direct current power transmission and power system protection.

Edgar L. Moreno Goytia

Olimpo Anaya-Lara

Graeme M. Burt 